\title{
Precision nanomedicine development based on specific opsonization of human cancer patient-personalized protein coronas
}

Jiayu Ren,${ }^{\dagger}{ }^{\S}$ Rong Cai, ${ }^{\dagger}$ Jing Wang, ${ }^{\dagger}$ Muhammad Daniyal,,${ }^{\dagger}{ }^{\S}$ Didar Baimanov, ${ }^{\dagger}{ }^{\S}$ Ying Liu, ${ }^{\dagger}$ Dongtao Yin, ${ }^{\bar{\top}}$ Yang Liu, ${ }^{\bar{\top}}$ Qing Miao, ${ }^{\dagger}$ Yuliang Zhao, ${ }^{\dagger,}{ }^{\S}$ Chunying Chen $^{\dagger,} \S, *$

${ }^{\dagger}$ CAS Key Laboratory for Biomedical Effects of Nanomaterials and Nanosafety and CAS Center for Excellence in Nanoscience, National Center for Nanoscience and Technology, Beijing 100190, China.

* State Key Laboratory of Natural and Biomimetic Drugs, School of Pharmaceutical Sciences, Peking University, Beijing 100191, China

${ }^{\bar{\top}}$ Department of Thoracic Surgery, Chinese PLA General Hospital, Beijing 100853, China

$\S$ University of Chinese Academy of Sciences, Beijing 100049, China

*Corresponding Author

Chunying Chen, Email: chenchy@ nanoctr.cn Tel: 8610-82545560 


\section{Materials and Methods}

Materials. Gd@ $\mathrm{C}_{82}(\mathrm{OH})_{22}$ NPs were synthesized as described in our previous report $^{13}$. Native human C1q protein (C1q, ab96363) was purchased from Abcam. Recombinant Complement Component 1q Subcomponent A (C1qA) (RPD207Hu01), Subcomponent B (RPD208Hu01) and Subcomponent C (RPE869Hu01) were purchased from Wuhan USCN Business Co. Ltd, China. Human fibrinogen (16088) was purchased from Cayman Chemical (USA). IgG was from Bioss Antibodies, China. Human serum albumin was from Beijing LABLEAD BIOTECH Co., Ltd, China. Transferrin (T3309) and NF-אB inhibitor (BAY 11-7082, $5 \mu \mathrm{M})$ were both purchased from Sigma- Aldrich.

\section{Cell culture and differentiation}

The THP-1 cells (University of California, Los Angeles, CA, USA), which was derived from the blood of an acute monocytic leukemia patient that can be differentiated into macrophages were used during the whole investigation process. They were cultured in RPMI 1640 medium (WISENT Inc., Quebec, Canada) supplemented with 10\% fetal bovine serum (FBS; Gibco, Langley, Oklahoma, USA) and 1\% antibiotics (100 $\mathrm{U} / \mathrm{mL}$ penicillin and $100 \mu \mathrm{g} / \mathrm{mL}$ streptomycin; Invitrogen, Carlsbad, CA, USA). Differentiation of THP-1 cells into macrophages were induced with the treatment of 100 ng/mL phorbol 12-myristate 13-acetate (PMA, Sigma Aldrich, Saint Louis, MO, USA) for 24 hours. Three times washed with the $1 \times$ PBS before the addition of NPs. All the cells were cultured under humidified atmosphere with $37^{\circ} \mathrm{C}, 5 \% \mathrm{CO}_{2}$.

\section{Nanoparticle uptake in macrophages}

For the endocytosis experiment, $5 \times 10^{5}$ cells/well were seeded on a 24 -well plate to 
be stimulated with $100 \mathrm{ng} / \mathrm{ml}$ PMA for $24 \mathrm{~h}$ to become macrophages prior to the experiment, and then washed one time with PBS followed by the addition of $\mathrm{Gd} @ \mathrm{C}_{82}(\mathrm{OH})_{22} \mathrm{NPs}(50 \mu \mathrm{M} /$ well), with and without pre-coating with C1q, for $6 \mathrm{~h}$. Following incubation, cells were collected after digestion with trypsin, washed three times with $\mathrm{PBS}$ and then counted. $3 \mathrm{ml}$ concentrated $\mathrm{HNO}_{3}$ was used to predigest cells overnight. The samples were digested and heated on a $300^{\circ} \mathrm{C}$ hot plate after mixing with $2 \mathrm{~mL} 30 \% \mathrm{H}_{2} \mathrm{O}_{2}$. After cooled to room temperature, the remaining solution (about $0.5 \mathrm{ml}$ ) was transferred to new tubes and diluted with $2 \% \mathrm{HNO}_{3}$ solution to a final mass of 2 grams. Serial of Gadolinium (Gd) standard solutions $(0,0.1,0.5,1$, 5, 10, 50 and $100 \mathrm{ppb}$ ) were prepared to obtain a standard curve. Bismuth (10 ppb) in $2 \% \mathrm{HNO}_{3}$ solution was used as an internal standard. All the tests were performed three times by ICP-MS.

\section{Enzyme-linked immunosorbent assay (ELISA)}

Cell culture supernatants to be collected after exposure $12 \mathrm{~h}$ to $\mathrm{Gd} @ \mathrm{C}_{82}(\mathrm{OH})_{22} \mathrm{NPs}$ with and without C1q pre-coating. The concentration of TNF- $\alpha$ and IL-1 $\beta$ were analyzed using a human TNF- $\alpha /$ IL-1 $\beta$ specific ELISA kit (eBioscience, USA) following the manufacturer's instructions. Briefly, the corresponding purified anti-human capture monoclonal antibody was attached to the 96-multiwell plate to stay overnight at $4^{\circ} \mathrm{C}$. A series of dilutions of the appropriate standards and culture supernatants were added to each well and incubated at $37^{\circ} \mathrm{C}$ for $2 \mathrm{~h}$. After washing three times, bound samples were detected at $37^{\circ} \mathrm{C}$ for $1 \mathrm{~h}$ using the corresponding biotinylated anti-human antibody. After washing another five times, an avidin-horseradish peroxidase solution was added and incubated at $37^{\circ} \mathrm{C}$ for $30 \mathrm{~min}$. After the final five washes, TMB substrate were added to the plates, held at $37^{\circ} \mathrm{C}$ for about 15 min until the dark 
blue color appeared. $50 \mu \mathrm{L}$ blocking solution ( $2 \mathrm{M} \mathrm{H}_{2} \mathrm{SO}_{4}$ solution) was applied to stop the reaction immediately, followed by the collection of absorbance at $450 \mathrm{~nm}$. We performed three independent experiments for each group.

\section{Multiple cytokines analysis}

Cell culture supernatants were collected after the various treatments, and the contents of 8 different cytokines (IL-1 $\beta$, TNF- $\alpha$, IL-2, IL-13, IL-6, IL-18, IL-12 p70, IL-4,) were measured using the Th1/Th2 Cytokine 11-Plex Human ProcartaPlex ${ }^{\mathrm{TM}}$ Panel (EPX110-10810-901; eBioscience, USA) according to the manufacturer's instructions.

\section{NF-кB immunofluorescence staining and confocal microscopy}

We performed a NF- $\kappa \mathrm{B}$ activation-nuclear translocation assay to test NF- $\kappa \mathrm{B}$ activity. Briefly, PMA-induced human macrophages were plated onto coverglass bottom dishes. After exposure to $\mathrm{Gd} @ \mathrm{C}_{82}(\mathrm{OH})_{22}$ for $0.5 \mathrm{~h}, 1 \mathrm{~h}, 2 \mathrm{~h}$ and $4 \mathrm{~h}$, the cells were fixed for 20 min with $4 \%$ paraformaldehyde at room temperature. After washing with PBS, $0.1 \%$ Triton X-100 was added to make the cells permeabilized, followed by blocking with $10 \%$ goat serum for $1 \mathrm{~h}$. The cells were then incubated with a NF- $\kappa \mathrm{B}$ p65 primary antibody (Affinity, AF5006, China) at $4^{\circ} \mathrm{C}$ overnight. The macrophages were incubated with an Alexa Fluor 594-conjugated secondary antibody for $1 \mathrm{~h}$ at room temperature followed by three times washed. Finally, the cell nucleus was stained with DAPI for $10 \mathrm{~min}$ at room temperature and washed three times with PBS, then visualized by confocal microscopy (Perkin Elmer Ultra View Vox system, USA). 


\section{Reverse transcription and real-time quantitative PCR (RT-PCR)}

First, the RNA was extracted from cells with the help of TRIZOL reagent (Life Technology, CA, USA). Moloney murine leukemia virus reverse transcriptase (M-MLV; Promega, Madison, USA) and 10 pmol olgonucleotide primer accompanied with $2 \mu \mathrm{g}$ RNA was used to carry out the reverse transcription. Real-time quantitative PCR was performed using Master Mix (Promega, Madison, USA) and SYBR® Green I (Invitrogen, Paisley, UK), the fluorescence intensity of SYBR® Green I was recorded to analyze the product during the cycle. The amplification cycle was programmed using Realplex 4 (Eppendorf, USA) as follows: $95^{\circ} \mathrm{C}$ for 2 min as an initial denaturing step, following by 40 cycles of denaturing $\left(95^{\circ} \mathrm{C}\right.$ for $\left.15 \mathrm{~s}\right)$, annealing $\left(55^{\circ} \mathrm{C}\right.$ for $\left.15 \mathrm{~s}\right)$ and extending $\left(72^{\circ} \mathrm{C}\right.$ for $\left.15 \mathrm{~s}\right)$. The primers (Sangon Biotec, Shanghai, China) used to detect the target genes by RT-PCR are the following: human TNF- $\alpha$-Forward $\left(5^{\prime}-3^{\prime}\right)$

GCCTGTAGCCCATGTTGTAGC, Reverse (5'-3') CCTGGGAGTAGATGAGGTACAGGC; human IL-1 $\beta$-Forward (5'-3') CTGCCCACAGACCTTCCAGG, Reverse (5'-3') TATGGACCAGACATCACCAAGCT; human GAPDH Forward (5'-3') CAACAGCCTCAAGATCATCAGC, Reverse (5'-3') TGAGTCCTTCCACGATACCAA.

\section{Protein corona formation and protein isolation}

Human plasma was collected from healthy volunteers and lung carcinoma patients, which were obtained from the Chinese People's Liberation Army (PLA) General Hospital, with approval of the hospital's ethics committee and complied with all relevant ethical regulations. The blood was allowed to clot at room temperature, and the plas-

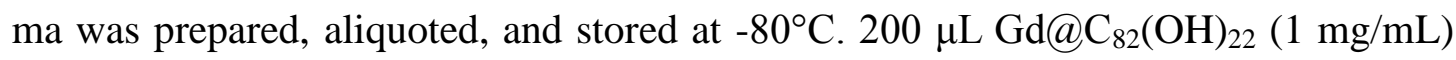
was mixed with $800 \mu \mathrm{L} \mathrm{10 \%} \mathrm{human} \mathrm{plasma} \mathrm{(} 80 \mu \mathrm{L}$ of human plasma and $720 \mu \mathrm{L}$ of 
buffer $\mathrm{A}[\mathrm{pH}=7.4])$ and incubated at $37^{\circ} \mathrm{C}$ for $1 \mathrm{~h}$. The above mixture was then centrifuged at $17,500 \mathrm{rpm}$ at $4^{\circ} \mathrm{C}$ for $30 \mathrm{~min}$. After removing the supernatant, the corona-coated Gd@ $\mathrm{C}_{82}(\mathrm{OH})_{22}$ NPs were re-dispersed in $1 \mathrm{~mL}$ cold $\left(4^{\circ} \mathrm{C}\right)$ buffer A. The suspension of $\mathrm{Gd} @ \mathrm{C}_{82}(\mathrm{OH})_{22} \mathrm{NPs}$ was centrifuged again at the same condition and the collected $\mathrm{Gd} @ \mathrm{C}_{82}(\mathrm{OH})_{22}$ NPs were suspended in $500 \mu \mathrm{L}$ cold buffer A. After three washing steps, the corona-coated particles were processed for LC-MS/MS.

\section{LC-MS/MS}

Liquid chromatography combined with tandem mass spectrometry (LC-MS/MS) was used to identify the NP-bound proteins (corona layer of $\mathrm{Gd} @ \mathrm{C}_{82}(\mathrm{OH})_{22} \mathrm{NPs}$ ). Briefly, The protein layer on the $\mathrm{Gd} @ \mathrm{C}_{82}(\mathrm{OH})_{22}$ NPs was extracted with SDT lysis buffer $(10 \%$ SDS, $100 \mathrm{mM}$ Tris-HCl, $1 \mathrm{mM}$ DTT, $\mathrm{pH}$ 7.6) $)^{41}$. The protein lysate was sonicated and then boiled for $15 \mathrm{~min}$. After centrifuging at $14,000 \times g$ for $40 \mathrm{~min}$, the total protein amount in the supernatant was quantified by using the BCA Protein Assay Kit (Bio-Rad, USA). Filter-aided sample preparation (FASP digestion) was performed for protein enzymolysis and high-performance liquid chromatography (HPLC) was performed for the purification. Afterwards, LC-MS/MS analysis was performed on a Q Exactive mass spectrometer (Thermo Scientific, USA) coupled to an Easy nLC device (Proxeon Biosystems, now Thermo Fisher Scientific, USA) for $60 \mathrm{~min}$. The MS data analysis and protein identification were used MaxQuant software version 1.3.0.5 (Max Planck Institute of Biochemistry in Martinsried, Germany) and UniProtKB Home sapiens sequence database (Released at Jan 2018, https://www.uniprot.org/). The cutoff of global false discovery rate (FDR) for peptide and protein identification was set to 0.01 . 


\section{Preparation of protein pre-coated $\mathrm{Gd} @ \mathrm{C}_{82}(\mathrm{OH})_{22}$ nanoparticles}

$200 \mu \mathrm{M} \mathrm{Gd} @ \mathrm{C}_{82}(\mathrm{OH})_{22}$ NPs were dispersed in $500 \mathrm{~mL}$ PBS $(0.1 \mathrm{M}, \mathrm{pH}=7.4) .20$ $\mu \mathrm{g} / \mathrm{mL}$ pre-coating protein (C1q, C1qA, C1qB, C1qC, HSA, IgG, FGB or Tf) solution was immediately added to the NP solution and stirred for $1 \mathrm{~h}$ in a $37{ }^{\circ} \mathrm{C}$ water bath. The final solution of NPs at a concentration of $50 \mu \mathrm{M}$ was used for all cell experiments.

\section{Surface plasmon resonance (SPR) analysis}

The SPR experiments were performed using a Biacore T200 system (GE Healthcare, USA) at $25^{\circ} \mathrm{C}$. The running buffer was PBS-P (10 mM phosphate buffer with $2.7 \mathrm{mM}$ $\mathrm{KCl}, 137 \mathrm{mM} \mathrm{NaCl}$, and $0.05 \%$ Surfactant P20) to quantify the interactions between $\mathrm{Gd} @ \mathrm{C}_{82}(\mathrm{OH})_{22}$ NPs and proteins; the proteins were immobilized on the surface of the CM5 sensor chip using the amine-coupling procedure. The immobilized levels of IgG, C1q, HSA, TF and FGB were $\sim 13,000, \sim 13,000, \sim 5,200, \sim 5,700$ and $\sim 4,600$ resonance units (RU), respectively. Subsequently, different concentrations of $\mathrm{Gd} @ \mathrm{C}_{82}(\mathrm{OH})_{22} \mathrm{NPs}$ were respectively injected at a flow rate of $30 \mu \mathrm{l} / \mathrm{min}$ with a contact time of $100 \mathrm{~s}$ and a dissociation time of $250 \mathrm{~s}$. After each binding experiment, the chip surface was regenerated by a $100 \mathrm{~s}$ injection of $2.5 \mathrm{M} \mathrm{NaCl}$ at a flow rate of 30 $\mu 1 /$ min. The data were analyzed by the Biacore T200 evaluation software (Version 2.0). The affinity constants $\left(\mathrm{K}_{\mathrm{D}}\right)$, association rate constants $\left(k_{\mathrm{a}}\right)$ and dissociation rate constants $\left(k_{\mathrm{d}}\right)$ were calculated by fitting the curves using a 1:1 kinetic binding model.

\section{Circular dichroism spectroscopy (CD)}

The alteration of the secondary structure of proteins bond on $\mathrm{Gd} @ \mathrm{C}_{82}(\mathrm{OH})_{22} \mathrm{NPs}$ surface was characterized by using a J-1500 circular dichroism spectrometer (JASCO, 
Japan). A 10-mm path length quartz cell was used, the sample was scanned over the range 190-300 $\mathrm{nm}$. Data were collected every $0.5 \mathrm{~nm}$ with a bandwidth of $1 \mathrm{~nm}$, at $100 \mathrm{~nm} \min ^{-1}$ and averaged over three scans. Proteins (C1q, IgG, FGB, TF or HSA) in PBS $(20 \mu \mathrm{g} / \mathrm{ml})$ were incubated with increasing concentrations of $\mathrm{Gd} @ \mathrm{C}_{82}(\mathrm{OH})_{22}$

NPs for 5 min at room temperature before each measurement. The final spectra were baseline-corrected and the data are presented as mean molar ellipiticity $(\theta)$. Based on the spectral data, the secondary structure estimation was performed. The percentage of secondary structure ( $\alpha$-helix, $\beta$-sheet, $\beta$-turn and random) was estimated using the parameters of Yang's reference.

\section{Tycho N.T6 for protein quality measurements}

The protein quality was evaluated by Tycho NT.6 's label-free thermal shift analysis. Briefly, we incubated $\mathrm{Gd} @ \mathrm{C}_{82}(\mathrm{OH})_{22}$ NPs with increasing concentrations of proteins (C1q, IgG, FGB, HSA or Tf), or for different incubation times at constant protein concentrations ( $0 \mathrm{~min}, 1 \mathrm{~min}, 10 \mathrm{~min}, 30 \mathrm{~min}, 60 \mathrm{~min}, 120 \mathrm{~min}$ ). The samples were loaded into precisely constructed glass capillaries by capillary attraction-only $10 \mu \mathrm{l}$ is needed for each measurement - which were then inserted into the device for analysis. Tycho NT.6 follows the unfolding process by recording sample fluorescence at $330 \mathrm{~nm}$ and $350 \mathrm{~nm}$ during thermal unfolding. A constant heating rate of $30^{\circ} \mathrm{C} / \mathrm{min}$ is applied to the sample, heating from $35^{\circ} \mathrm{C}$ to $95^{\circ} \mathrm{C}$.

\section{Western Blot and ELISA assays for complement activation in vitro}

Western Blot Analysis. To assess complement activation induced by NPs, $40 \mu \mathrm{L}$ 
C1q-depleted human serum (Merck, Germany) was incubated with $250 \mu \mathrm{M}$ $\mathrm{Gd} @ \mathrm{C}_{82}(\mathrm{OH})_{22} \mathrm{NPs}$ at a ratio of 1:4 (v/v) at $37^{\circ} \mathrm{C}$ for $30 \mathrm{~min} . \mathrm{C} 1 \mathrm{q}(180 \mu \mathrm{g} / \mathrm{ml}$; Sigma, USA), $\mathrm{C} 1 \mathrm{qA}, \mathrm{C} 1 \mathrm{qB}$ or $\mathrm{ClqC}(60 \mu \mathrm{g} / \mathrm{ml}$; USCN, China) was added to the C1q-depleted serum before NPs' addition. Saline was used as a negative control for complement in all experiments. BCA protein assay (Thermo Fisher Scientific, Australia) was used to quantify the protein concentration. $20 \mu \mathrm{g}$ protein was resolved by SDS-polyacrylamide gel electrophoresis (SDS-PAGE; 8\% polyacrylamide) and subsequently transferred onto a polyvinylidene difluoride membrane (Bio-Rad, USA). The membrane was blocked with a 5\% skim milk solution for $1 \mathrm{~h}$ at room temperature, and then incubated with the primary antibody overnight at $4^{\circ} \mathrm{C}$, and further incubated with the corresponding secondary antibody for $1 \mathrm{~h}$ at room temperature. The proteins were visualized with an ECL-plus detection system (Millipore, USA) following by washing three times with TBST (Tris-Buffered Saline contained 0.5\% Tween 20). The primary antibodies included C4b (Abcam, USA) and C3b/iC3b (Abcam, USA). ELISA. Complement activation induced by $\mathrm{Gd} @ \mathrm{C}_{82}(\mathrm{OH})_{22} \mathrm{NPs}$ and C1q pre-coated $\mathrm{Gd} @ \mathrm{C}_{82}(\mathrm{OH})_{22}$ NPs in human serum was quantified by testing the NP-induced rise of complement activation products C3a (Human C3a ELISA Kit, USA) and C5a (Human C5a ELISA Kit, eBioscience, USA) following the manufacturers' instructions. Gd@ $\mathrm{C}_{82}(\mathrm{OH})_{22}$ NPs and C1q pre-coated Gd@ $\mathrm{C}_{82}(\mathrm{OH})_{22}$ NPs were incubated with 75\% (v/v) human serum (in triplicate) at $37^{\circ} \mathrm{C}$ for $30 \mathrm{~min}$ in a shaking water bath. The complement activating reactions were terminated by saline containing $25 \mathrm{mM}$ EDTA provided by the assay kit. The complement activation products (C3a and $\mathrm{C} 5 \mathrm{a})$ induced by Gd@ $\mathrm{C}_{82}(\mathrm{OH})_{22}$ NPs and C1q pre-coated $\mathrm{Gd} @ \mathrm{C}_{82}(\mathrm{OH})_{22}$ NPs were measured by spectrophotometer after reaction termination and NPs removal. Background complement activation was estimated by incubating human serum with saline. 


\section{Statistical analysis}

All data values are descripted as the Mean values \pm standard derivation (S.D). Triplicated experiments were performed for all experiments in this study. All the statistical analyses were performed using GraphPad Prism 7.0 (GraphPad Software). Statistical significance was assessed by Student's t-test. $p<0.05$ was considered to indicate statistical significance. $* p<0.05, * * p<0.01$ and $* * * p<0.001$.

a

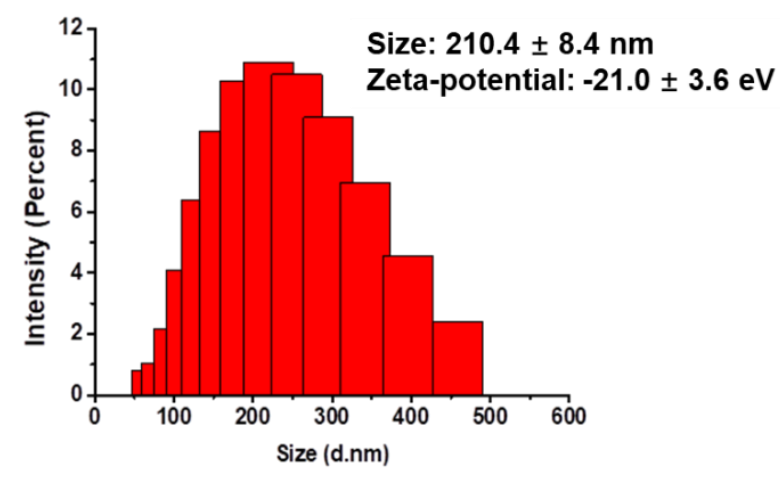

b

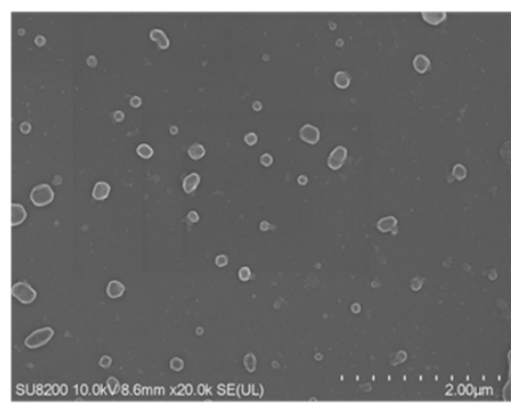

Figure S1. Characterization of Gd@ $\mathrm{C}_{82}(\mathrm{OH})_{22}$ nanoparticles. (a) The hydrodynamic size of $\mathrm{Gd} @ \mathrm{C}_{82}(\mathrm{OH})_{22}$ nanoparticles is $210.4 \pm 8.4 \mathrm{~nm}$ and the zeta potential is $-21.0 \pm 3.6 \mathrm{eV}$, which was characterized by dynamic light scattering (DLS). (b) $\mathrm{Gd} @ \mathrm{C}_{82}(\mathrm{OH})_{22}$ nanoparticles were dispersed in aqueous solutions ( $\mathrm{pH} 7.0$ ) with an average diameter of $163.7 \pm 35.6 \mathrm{~nm}$ as determined by SEM. 
a

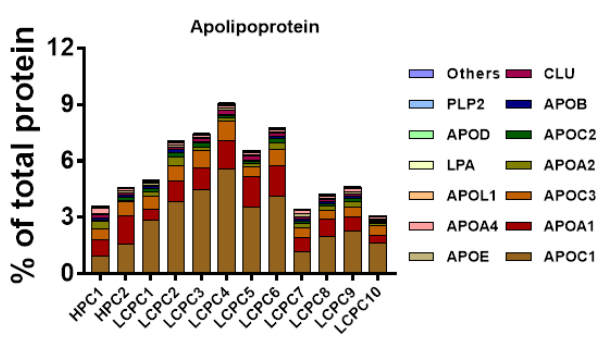

b

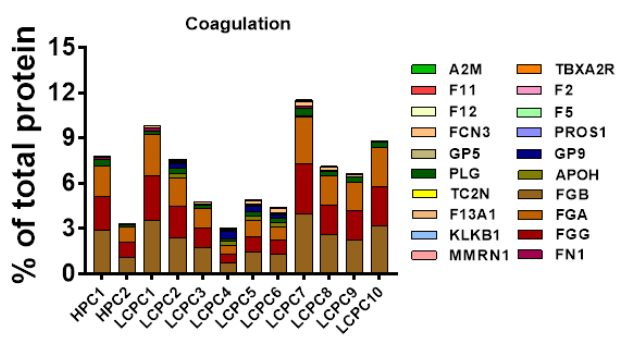

Figure S2. Identification of apolipoproteins and hemostasis (coagulation) proteins in lung cancer-personalized coronas formed on $\mathrm{Gd} @ \mathrm{C}_{82}(\mathrm{OH})_{22}$ NPs. (a) The percentage of identified apolipoprotein components in both healthy protein coronas (HPC) and lung cancer protein coronas (LCPC) on the surface of $\mathrm{Gd} @ \mathrm{C}_{82}(\mathrm{OH})_{22}$ NPs. APOC1 showed a notably greater abundance in LCPC. (b) The percentage of coagulation components from coronas formed from HPC and LCPC show that FGA, FGB and FGG were the top three most abundant components of this class of proteins.

a

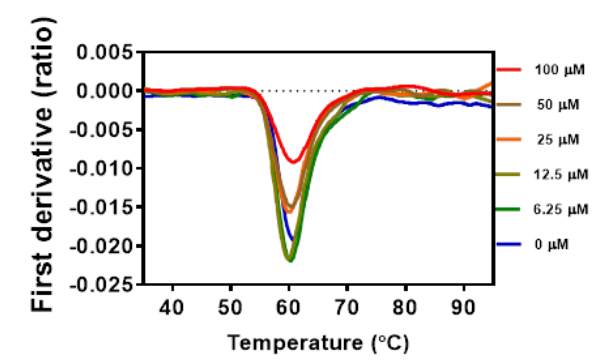

b

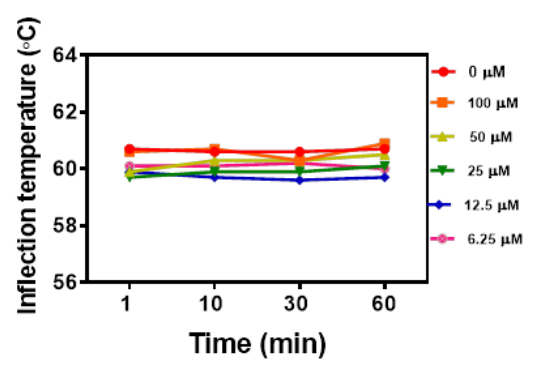

Figure S3. Characterization of the folding status of C1q after treatment with $\mathrm{Gd} @ \mathrm{C}_{82}(\mathrm{OH})_{22}$.

(a) The first derivative of the ratio of fluorescence $350 \mathrm{~nm} / 330 \mathrm{~nm}$ mirrors the integrity of $\mathrm{C} 1 \mathrm{q}(20 \mu \mathrm{g} / \mathrm{ml})$ in the presence of increasing amounts of $\mathrm{Gd} @ \mathrm{C}_{82}(\mathrm{OH})_{22}$ NPs. (b) The inflection temperature (Ti) was calculated from the fluorescence recorded during the thermal run. 

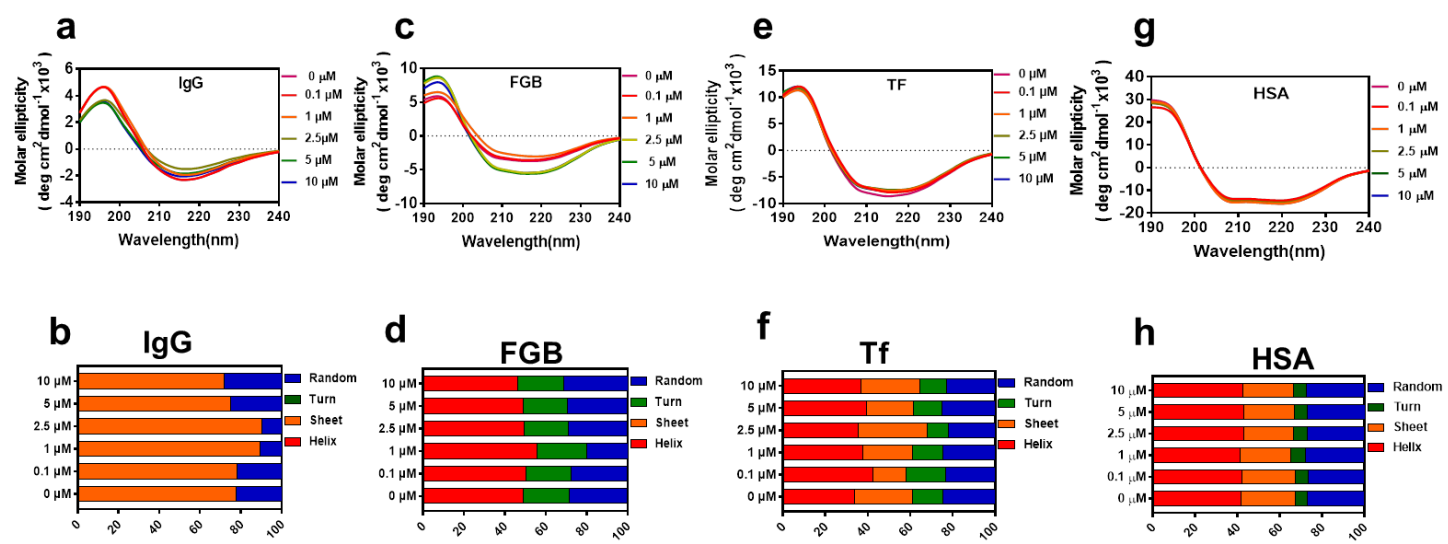

Figure S4. Circular dichroism spectrum characterization of the structure of selected proteins (IgG, FGB, Tf and HSA) after treatment with $\mathrm{Gd} @ \mathrm{C}_{82}(\mathrm{OH})_{22}$ NPs. (a, c, e, g) Circular dichroism of IgG (a), FGB (c), TF (e) and HSA (g) in the absence or presence of increasing concentrations of $\mathrm{Gd} @ \mathrm{C}_{82}(\mathrm{OH})_{22}$ NPs. (b, d, f, h) The corresponding secondary structures according to estimation parameters (Yang's reference).

a

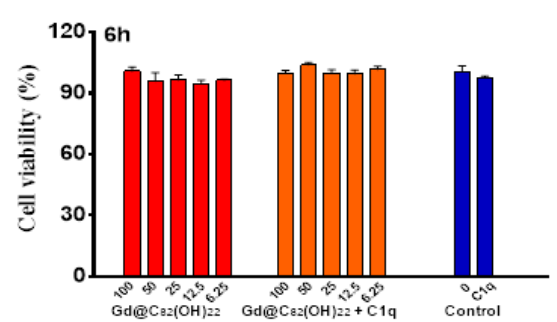

b

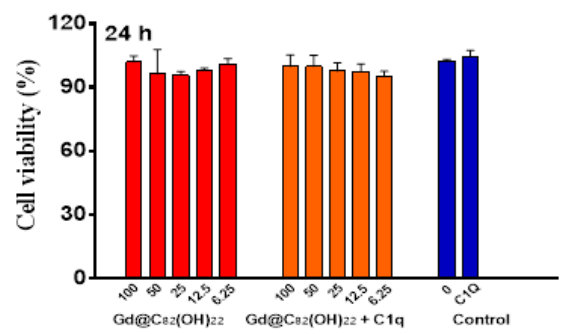

Figure S5. (a, b) Evaluation of cell viability by CCK- 8 assay. Macrophages were treated with NPs for $6 \mathrm{~h}$ (a) and $24 \mathrm{~h}$ (b) in culture medium without any supplemented serum. No decrease in the cell viability was observed. 

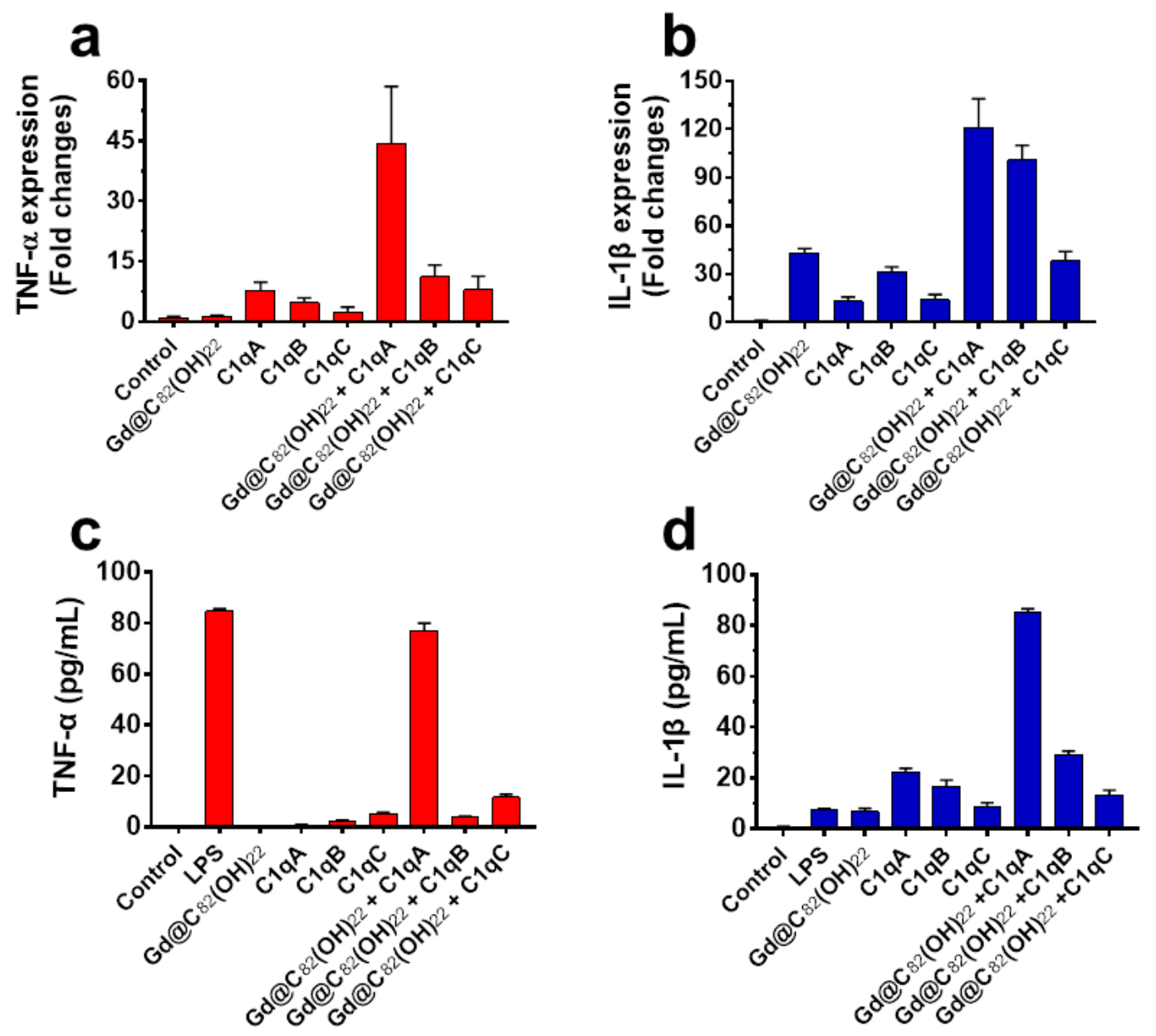

Figure S6. Immunological effects of $\mathrm{Gd} @ \mathrm{C}_{82}(\mathrm{OH})_{22}$ NPs pre-coated with C1qA, B or C in PMA-induced human macrophages. The expression levels of TNF- $\alpha$ (a) and IL-1 $\beta$ (b) were analyzed by qPCR. ELISA analysis of pro-inflammatory cytokines TNF- $\alpha$ (c) and IL-1 $\beta$ (d) in the supernatant from the cell culture medium. The data are presented as the mean \pm s.d. $(n=3)$. 